\title{
LA HEGEMONÍA EN EL PODER Y DESARROLLO TERRITORIAL
}

Apolinar Oliva Velas

CUITT

UNIVERSIDAD AUTÓNOMA DE CHIAPAS

Alma E. Isunza Bizuet

LEGAI

UNIVERSIDAD AUTÓNOMA DE CHIAPAS

\section{RESUMEN}

El presente ensayo busca explicar cómo la construcción de la relación entre las elites que forman parte del Estado y los grupos sociales que son dirigidos y dominados por el propio Estado —en términos de Gramsci la relación Estado y sociedad civil— generan un tipo de proyecto nacional que impacta al conjunto de territorios, que desde nuestra perspectiva operan como un sistema territorial que compone a un Estado nación. Las condiciones de desarrollo de cada territorio y del conjunto del sistema están afectadas por cómo se estructuran las relaciones entre los grupos de poder local y los grupos de poder central del Estado. Con estas herramientas analíticas se construye una explicación de la relación histórica que se va erigiendo en el México posrevolucionario entre ambos poderes que afecta al desarrollo territorial.

Palabras clave: hegemonía, desarrollo territorial, grupos de poder, políticas públicas. 


\begin{abstract}
Based upon a gramscian perspective, this paper seeks to explain how the relationship between the State and civil society generates a type of national project that impacts all its territories. Refering to mexican postrevolutionary experience, it is pointed out that development conditions in each territory and in the entire system are affected by the structure of interactions between the local power groups and the State's central power groups.
\end{abstract}

Key words: hegemony, territorial development, power groups, public policies. 


\section{INTRODUCCIÓN}

La teoría territorial del desarrollo, menciona Vázquez 1999, tiene exponentes relevantes como Stöhr y Todtling, además de Sach, Friedman y Weaver, quienes comparten el mismo concepto de territorio que presenta el desarrollo local endógeno. Ambas perspectivas consideran que cada territorio es el resultado de una historia en la que se ha ido configurando el entorno institucional, económico, organizativo; lo que le otorga una identidad propia y le permite dar respuestas estratégicas a los desafíos que se presentan.

Consideramos en el marco analítico que cada nación está constituida por un conjunto de territorios que operan como un sistema, donde cada territorio genera una serie de procesos económicos, sociales y culturales, que componen una red de relaciones entre los actores sociales que lo habitan. Asimismo partimos de que el ámbito nacional está constituido por un sistema de territorios interconectados, donde cada uno tiene procesos endógenos que le afectan e influyen al resto del sistema, a la vez que están siendo perturbados por los otros elementos.

Los diversos territorios operan dentro de un marco general de reglas, unas son generadas por el Estado o por los acuerdos internacionales que el propio Estado decide acatar y aplicar, otras se insertan en el conjunto de reglas formales e informales que se producen en el territorio; por otro lado, los territorios resultan afectados por los movimientos de bienes, servicios, personas, conocimientos, información, códigos y símbolos culturales, producidos dentro o fuera de él.

La posibilidad de generar desarrollo en los territorios depende en gran parte de la capacidad que tiene la sociedad de liderar aquellos procesos que desarrollen habilidades y competencias de los agentes del territorio, que les permitan estructurar un conjunto de reglas que impulsen la cooperación y el desarrollo de infraestructura para generar ventajas 
competitivas, internalizando en las empresas estas condiciones exógenas, mejorando los procesos de distribución del ingreso, incrementando los niveles de salud, educación, así como el disfrute pleno de los derechos políticos y civiles en el marco de reconocimiento de la diversidad.

El presente documento recupera el concepto de hegemonía de Gramsci para explicar el comportamiento del bloque hegemónico en territorios específicos; si bien sus propuestas se encuadran dentro de una teoría revolucionaria que tiene por objetivo una trasformación radical de la sociedad, algunos planteamientos que analizan la estructura del poder en la sociedad capitalista se pueden utilizar para examinar el impacto de los grupos sociales en la disputa y ejercicio del poder en los procesos de desarrollo territorial, debido a que los «grandes pensadores» como Gramsci generan explicaciones del mundo concreto en el que viven, independientemente de las sociedades utópicas que deseen construir.

En el proceso de análisis utilizaremos conceptos derivados de los planteamientos del desarrollo local endógeno como una vertiente de las teorías del desarrollo territorial. Se parte de que para lograr procesos de desarrollo, las políticas públicas son elementos esenciales que pueden mover a un sistema territorial hacia situaciones de mejora de los indicadores del desarrollo. Planteamos que no existe un tipo único de diseño institucional que genere las mejores políticas públicas, por lo que surge la necesidad de buscar un modelo que asuma el pluralismo regional como principio rector.

Lo anterior reconoce que el indicador final del desarrollo es la constitución de individuos con capacidad de agencia, entendida ésta como la posibilidad de que los individuos se apropien de los procesos sociales de manera que organizados en redes económicas, sociales, políticas y culturales, gestionen los recursos territoriales para mejorar de manera generalizada la calidad de vida de todos los habitantes del territorio. 
Las políticas públicas son procesos de intervención que pueden incidir de manera rápida y eficiente en cambiar el estado de un sistema territorial. Debido a que una de las funciones esenciales del Estado es el diseño y aplicación de políticas públicas, estructuramos nuestro análisis partiendo del supuesto gramsciano de la existencia, al interior del Estado, de un bloque histórico en el poder, y que este bloque no es homogéneo puesto que se encuentra conformado por diferentes grupos sociales, los cuales en la medida de que son capaces de generar un proyecto, pueden ejercer no solo la dominación sino además la dirección de la sociedad.

El tipo de proyecto que construye el grupo dirigente del bloque hegemónico en el poder, si es innovador e incluyente puede generar mejores condiciones de vida en el conjunto de la sociedad, además de que como grupo dirigente obtendrá mayor legitimidad en el ejercicio de dicho poder.

Partimos de un doble reconocimiento, primero, que tanto en la construcción de la agenda como en el diseño de las políticas públicas son consideradas las demandas de aquellos grupos sociales con mayor capacidad de gestión y de presión; segundo, que estos grupos representan el dato «duro» de la construcción de hegemonía político-económica que se estructura en cada uno de los territorios.

Algunas corrientes teóricas plantean que existe una división entre la política como ejercicio de conquista y retención del poder y la política como acción de gobierno — politics y policies_, Gramsci plantea que hay una unidad entre estas dos condiciones porque el ejercicio del poder a través de políticas públicas está influido por el grupo social que ejerce la supremacía a través del dominio y la dirección intelectual y moral; esto es, en palabras de Gramsci, existe un grupo social en el poder que ejerce dominio y dirección. 
Entonces, el tipo de políticas públicas generadas por el grupo social que detenta el poder estará definido por la composición particular del bloque hegemónico a partir de los grupos económicos, políticos y sociales, así como por los intelectuales que sirvan al proyecto del grupo hegemónico.

Según la tesis gramsciana las condiciones de desarrollo de una nación se estructuran a partir de cómo el grupo hegemónico dirige el proceso. Sin embargo, el autor hace un análisis macro de la política donde su unidad de análisis es la nación, así considera que el grupo social nacional que tiene la hegemonía puede ejercer su dominio y dirección en todo el territorio nacional mediante un proceso orgánico de relación entre gobernantes y gobernados.

Encontramos a grupos sociales que operan en un amplio margen territorial y por ende afectan directamente a cierto subconjunto del territorio. De igual manera, por ser un sistema, afectarán de manera indirecta al resto de los elementos del territorio. Por otra parte, encontramos a grupos sociales que operan solamente en espacios territoriales reducidos, y por ello su impacto será más intenso sobre ese territorio.

En nuestra realidad mexicana, como en la de cualquier otro Estado nación, encontramos que los grupos sociales que ejercen el poder son heterogéneos y tienen intereses diferenciados en las diversas unidades territoriales -municipio, estado y nación-, sus intereses en algunos casos se traslapan en las diversas unidades territoriales. En muchos casos los grupos sociales con intereses en todo el territorio nacional, como los partidos políticos, Iglesias, grandes empresas, también generan vacíos o una actividad restringida en diversos territorios del país.

El problema es considerar cómo se da la mediación entre el proyecto nacional y los intereses de las unidades territoriales, porque como señala el autor referido los procesos 
sociales se construyen desde abajo, y si no existe una dirección eficiente que genere consenso y legitimidad únicamente se dará un proceso de yuxtaposición de unidades particulares sin nexo alguno entre ellas.

Debe existir un proceso de interacción concreto entre el grupo social nacional que ejerce la hegemonía y los grupos localizados territorialmente, que al mismo tiempo son los grupos hegemónicos locales que ejercen el poder y que en algunos momentos alcanzan proyección en la esfera nacional, y parte de éstos juegan el papel de intermediarios entre los grupos centrales y los grupos locales.

\section{EL CONCEPTO DE POLITICS-POLICIES FRENTE AL DE GRUPO HEGEMÓNICO}

Dentro de un análisis sistémico de la política hay quienes consideramos a ésta como un elemento explicativo de la construcción de otros procesos sociales, de tal manera que la forma como se obtiene y mantiene el poder y la manera como se ejerce generan un conjunto de efectos sobre el desarrollo económico, social y cultural de un sistema territorial específico.

El análisis teórico de la política que inició con los griegos y romanos, sintetizadores del pensamiento racional occidental, se adormece en el medioevo y renace con Maquiavelo, quien propone una concepción de la teoría política como el análisis del proceso de conquista y mantenimiento del poder; luego con los pensadores renacentistas y poco más tarde con los ilustrados se presentan nuevas ideas paralelamente con el desarrollo de los Estados nacionales.

Los pensadores del siglo XVIII hasta nuestros días centran el análisis de la política en la construcción de estructuras institucionales que permitan el ejercicio del poder del 
Estado sin menoscabo de los derechos humanos, de las libertades civiles e individuales de los gobernados.

\begin{abstract}
Maquiavelo escribía de política como la había practicado; del arte de adquirir el poder y conservarlo, y de los errores que debe de evitar un príncipe para mantenerse en el ejercicio de sus funciones. Para él los medios eran tan fascinantes que nunca pareció preocuparse acerca del fin (Grossman 1986:
\end{abstract} 29).

Mientras que con el nacimiento y evolución del Estado nación, la preocupación central de la ciencia política por varios siglos — desde los autores clásicos de la disciplina como Hobbes, Locke, Stuart Mill, Voltaire, Rousseau, Paine, entre otros- consistió en explicar el diseño institucional del Estado que fuera más adecuado para que la sociedad política disputara el poder sin violencia y sirviera para darle unidad y gobernabilidad a la nación sin que las personas que ocuparan los cargos en este diseño institucional abusaran del poder.

Después la preocupación fundamental de esta vertiente de la ciencia política fue diseñar los mecanismos institucionales para generar un sistema político democrático donde la participación de la sociedad civil fuera capaz de generar los incentivos para impulsar un Estado respetuoso de los derechos humanos, de los derechos políticos y civiles, además de eficiente en el ejercicio de gobierno.

A mediados del siglo $\mathrm{XX}$, un grupo de investigadores vinculados con la administración pública comienza a plantear la importancia del diseño institucional; no obstante considerando la democracia como la forma de gobierno más adecuada para la relación entre Estado y sociedad civil, el problema central de estudio se ubica en cómo 
dentro de una sociedad democrática los gobernantes toman decisiones para resolver los problemas concretos de la sociedad del momento en un periodo de tiempo concreto.

A este planteamiento de cómo puede un gobierno democrático tomar las mejores decisiones a partir de los recursos con que cuenta se le denominó ciencia de la política, traducción forzada del término en inglés policy sciences. El concepto tiene su origen en Harold Lasswell, quien coordinó en Estados Unidos un equipo multidisciplinario durante la Segunda Guerra Mundial que asesoró al gobierno para la toma de decisiones de los políticos a través de la oficina División experimental para el estudio de las comunicaciones en tiempos de guerra.

El concepto de Ciencias de política[s] fue propuesto por Harold Lasswell en 1951, durante los años trascurridos desde entonces se han inventado o desarrollado significativamente muchos dispositivos de las ciencias de política, tales como la investigación de operaciones, el análisis de sistemas, la teoría de juegos, la cibernética, la teoría general de sistemas, el análisis estratégico y la ingeniería de sistemas, junto con varias ramas y aspectos de las ciencias sociales aplicadas (Dror 1996: 119).

De esta manera se formó una ramificación disciplinaria en la ciencia política, misma que plantea una nueva ruta del conocimiento considerando que para el análisis de las políticas públicas existe un diseño institucional democrático que permite resolver una serie de contradicciones, generando equilibrios entre el Estado y la sociedad civil, y que lo importante es ver la manera como un gobierno diseña, elabora y aplica las políticas públicas. Se plantea que el objeto de estudio de esta disciplina es:

... mejorar la relación entre el conocimiento natural y social que una sociedad posee en su comunidad intelectual y las decisiones [de] los gobernantes y legisladores ... Pero no es cualquier 
decisión de política su objeto de conocimiento. Su foco analítico son las decisiones relativas a los problemas del hombre en sociedad, a los conflictos básicos de nuestra sociedad y en positivo la plena realización de la dignidad humana, sin embargo para esta disciplina solo importan las decisiones políticas democráticas en tanto decisiones sustancialmente públicas, en busca de representatividad y racionalidad colectiva son las que requieren de la función inteligencia. En la democracia de matriz liberal el nexo entre decisión y racionalidad es intrínseco e imperativo (Aguilar 1996: 47-48).

Sin embargo, esta concepción de decisiones racionales aplicadas por una estructura definida comienza a ser cuestionada aun desde la óptica de la separación entre el acceso al poder y el ejercicio de gobierno. Diversos autores cuestionan la racionalidad del sistema democrático al observar que la eficiencia del sistema puede ser demasiado baja, ya que a pesar de un diseño racional de las políticas públicas existen fuertes problemas en su implementación.

... la imagen de organización como un sistema racional percibe que los arreglos estructurales dentro de la organización están establecidos en forma deliberada y diseñados para obtener eficientemente ciertos fines previamente establecidos. Desde este punto de vista, la racionalidad reside más en la estructura organizacional y no tanto en los individuos que la componen, por lo tanto es mejor concebir a la organización como un sistema natural y abierto donde se perciba los fines de la organización y el comportamiento de los individuos de una forma mucho más compleja para entender los objetivos formales de la organización y los objetivos e intereses de los individuos que operan dentro de la organización (Coronilla y Castillo 2000: 84).

Por otra parte, también se busca redefinir el concepto de Estado y sociedad civil dentro de la ciencia política en la búsqueda de una comprensión profunda de sus relaciones buscando redefinir los límites entre lo público y lo privado 
La democratización o masificación de la política supone no solo su difusión y si se quiere su dilución, sino sobre todo su ubicuidad. A la ubicación vertical se une ahora una expansión y ubicación horizontal; lo que vuelve a subvertir de nuevo todo el discurso. Después de milenios de relativa quietud ¡cuántos sacudimientos en más de un siglo! En la medida que el Estado se extienda los procesos políticos no podrán ser situados en el ámbito del Estado y de sus instituciones. De hecho y por consecuencia, el concepto se amplía y es sustituido por un concepto bastante más elástico, y abarcador de sistema político. El sistema político no solo se descompone en subsistemas, algunos de los cuales — por ejemplo el subsistema partidista y el subsistema de grupos de presión- quedan excluidos de la perspectiva institucional, sino es tan flexible como para permitir que se incorporen algunas variantes particulares; por ejemplo, el subsistema militar cuando los militares hacen política; el subsistema sindical cuando el sindicato se convierte en una potencia en sí misma, y así sucesivamente (Sartori 2003: 220).

Frente a los planteamientos anteriores de diferenciación de análisis de la política en dos procesos, el primero de acceso y mantenimiento del poder — política-, y el segundo de ejercicio del poder mediante las políticas públicas considerando procesos fragmentados; existe un enfoque alterno desde la perspectiva teórica gramsciana donde se plantea la política como proceso unitario dentro del funcionamiento de la sociedad. Teniendo en cuenta que en el proceso los grupos sociales establecen alianzas para construir un proyecto de sociedad, uno de ellos ejerce la hegemonía logrando consenso dentro de estos grupos, y el bloque hegemónico despliega un proceso de dominio sobre el resto de la sociedad; este dominio se da tanto mediante el consenso ideológico como por la coerción.

Por ahora se pueden fijar dos grandes planos sobrestructurales; el que puede llamarse de la «sociedad civil», o sea, del conjunto de los organismos vulgarmente llamados «privados», y el de la «sociedad 
política o Estado», los cuales corresponden, respectivamente, a la función de «hegemonía» que el grupo dominante ejerce en toda sociedad y a la de «dominio directo» o de comando que se expresa en el Estado y en el gobierno «jurídico». Estas funciones son precisamente organizativas y conectivas. Los intelectuales son los «empleados» del grupo dominante para el ejercicio de las funciones subalternas de la hegemonía social y del gobierno político, a saber: 1) del «consenso» espontáneo que las grandes masas de la población dan a la dirección impuesta a la vida social por el grupo fundamental dominante, consenso que históricamente nace del prestigio - y por lo tanto de la confianza- que el grupo dominante deriva de su posición y de su función en el mundo de la producción; 2) del aparato de coerción estatal que asegura «legalmente» la disciplina de aquellos grupos que no «consienten» ni activa ni pasivamente, pero que el mismo está preparado para toda la sociedad en previsión de los momentos de crisis en el comando y en la dirección, casos en que no se da el consenso espontáneo (Gramsci 1981a: 394).

Desde la perspectiva gramsciana se parte de que el diseño democrático, llamado centralismo por este autor, continúa siendo una forma de dominación. Sin embargo este diseño institucional más elástico permite que el bloque hegemónico se amplíe y su forma de generar consensos sea legitimadora, de manera que el dominio y dirección del Estado sobre la sociedad civil ocurra sin grandes conflictos. En el desarrollo del capitalismo y en el nacimiento de la clase denominada burguesa, Gramsci considera revolucionaria la burguesía por su concepción del derecho y la función del Estado.

Las clases dominantes anteriores eran esencialmente conservadoras en el sentido de que no tendían a elaborar una transición orgánica de las demás clases a la suya, o sea, a ampliar técnica e ideológicamente su esfera de clase: su concepción era la de casta cerrada. La clase burguesa se pone a sí misma como organismo en movimiento continuo capaz de absorber toda la sociedad, asimilándola a su nivel cultural y económico: toda la función del Estado se trasforma (Gramsci 1981b: 316). 


\section{EL CONCEPTO DE DESARROLLO TERRITORIAL Y LA HEGEMONÍA}

Partimos de que el desarrollo territorial considera la constitución del territorio a partir de los siguientes componentes: a) los recursos naturales, b) la estructura institucional, y c) la red de relaciones para los procesos económicos, sociales y culturales; estos componentes se desarrollan en un proceso histórico que configura a individuos insertos en una sociedad local con capacidad estratégica para resolver los desafíos que se puedan presentar. Los diversos planteamientos del desarrollo local son un enfoque sistematizado de los argumentos más relevantes del desarrollo territorial (Vázquez 1999, Moncayo 2002).

Otro de los elementos que diferencia las teorías del desarrollo local respecto a otras teorías como las del desarrollo regional es la idea de que no hay una sola ruta para alcanzar el desarrollo, ni que el desarrollo sea una condición a la cual forzosamente todo territorio llegará (Moncayo 2002, Galicchio 2004).

Así que uno de los factores que explica el proceso de desarrollo local es la capacidad para utilizar los recursos del territorio, constituyéndose en eje central la capacidad innovadora y adaptativa del territorio a las condiciones cambiantes de la sociedad, esta depende de cómo el grupo social hegemónico, en cada territorio particular, genera consenso y dirección en un proceso; donde se requiere que el grupo hegemónico local mantenga coherencia y unidad de los intereses locales dentro del marco institucional nacional e internacional; y que además sea capaz de constituirse en un centro donde los diversos intereses de los grupos del bloque hegemónico procesen sus contradicciones y puedan crear el consenso necesario entre los grupos sociales subordinados.

Como plantea Buci-Glucksmann, el concepto analítico de hegemonía de Gramsci permite plantear, fuera de los términos de blanco y negro polarizado — desde los diferentes 
autores marxistas-, ser el instrumento de control de la sociedad por parte de la burguesía, o la visión de un Estado árbitro neutro que permite que todos los grupos sociales diriman sus contradicciones.

Si la tradición marxista ha hecho siempre hincapié de forma privilegiada en las formas de dominación, Gramsci saca a la luz el papel decisivo y complementario de las formas de dirección en el conjunto de la vida social —económica, política y cultural...—, pues sobre todo es preciso no caer en la trampa de las palabras: la hegemonía no se identifica en lo absoluto con la fuerza. La hegemonía de una clase es un proceso histórico, no se impone se conquista mediante una política de alianzas que abre una perspectiva nacional al conjunto de la sociedad haciéndole avanzar. Y esta conquista, esta práctica expansiva de nuevas relaciones entre los partidos, los sindicatos, las instituciones democráticas de base y de masas constituye una nueva práctica de la política y de la teoría (Buci-Glucksmann 1979: 9).

El problema de trabajar el concepto de sistema territorial junto con el de hegemonía gramsciana consiste en definir cómo se interrelaciona la acción de los grupos hegemónicos que operan en cada territorio y de qué manera se articulan; al ser un conjunto formado por elementos, que son las unidades territoriales, surge la cuestión de definir cuáles son las acciones que atraviesan a todo el sistema y cuáles las que tienen ámbitos de acción reducidas a unas cuantas unidades territoriales.

Para Gramsci el grupo social que ejerce la supremacía debe tener capacidad de dirección y dominio. En la primera fase de construcción social del Estado nación, la necesidad esencial del grupo que ejerce la supremacía es constituir un proyecto de unidad nacional que permita florecer la sociedad capitalista, así fue en el caso italiano —que a él le preocupó analizar-, viendo cómo se pasa de un conjunto de municipios dispersos e 
inconexos en su dirección a una nación con un Estado que puede generar reglas de aplicación en todo el territorio. En el proceso los grupos con intereses muy localizados en estas unidades subnacionales deben subordinarse con el fin de generar un conjunto de reglas que permita operar al Estado en la consolidación de la construcción de la nación.

Antes de la Revolución Francesa, es decir, antes de que se constituyese orgánicamente una clase dirigente nacional, había una emigración de elementos italianos representantes de la técnica y de la capacidad directiva, elementos que enriquecieron a los Estados europeos con su contribución. Luego de la formación de una burguesía nacional y luego del advenimiento del capitalismo, se inició la emigración del pueblo trabajador, que fue a aumentar la plusvalía de los capitalismos extranjeros; la debilidad nacional de la clase dirigente siempre influyó negativamente. La clase dirigente no le dio disciplina nacional al pueblo, no lo ha hecho salir del municipalismo hacia una unidad superior, no ha creado una situación económica capaz de reabsorber las fuerzas de trabajo emigradas, de modo que esos elementos se han perdido en gran parte, incorporándose a las nacionalidades extranjeras en función subalterna (Gramsci 2008a).

El criterio metodológico en el cual hay que fundar el examen es éste: que la supremacía de un grupo social se manifiesta de dos modos, como «dominio» y como «dirección intelectual y moral». Un grupo social es dominante respecto a los grupos adversarios que tiende a «liquidar» o a someter incluso con la fuerza armada, y es dirigente de los grupos afines o aliados. Un grupo social puede y hasta tiene que ser dirigente ya antes de conquistar el poder gubernativo - esta es una de las condiciones para la conquista del poder-; luego cuando ejerce el poder y aunque lo tenga firmemente en las manos, se hace dominante, pero tiene que seguir siendo también «dirigente». (Gramsci 1981c: 486).

Gramsci pensaba que la elite empresarial juega un papel preponderante en la organización de la sociedad por la manera en que organiza el proceso productivo y expande su propia 
clase; consideró además que uno de los elementos relevantes de la producción capitalista es la capacidad de expandir la clase tanto en términos de número de empresarios como ideológicamente, y manifestó su asombro ante la percepción de reproducción social de esta clase dirigente.

Una elite, al menos, de los empresarios, si no todos, ha de tener una capacidad de organización de la sociedad en general, en todo su complejo organismo de servicios, hasta llegar al organismo estatal, por la necesidad de crear las condiciones más favorables para la expansión de la propia clase, o ha de tener al menos la capacidad de escoger los «administradores»—empleados especializados— a los que confiar esa actividad organizativa de las relaciones generales exteriores a la empresa. Puede observarse que los intelectuales «orgánicos» producidos por cada nueva clase al constituirse ella misma en su progresivo desarrollo son en su mayor parte «especializaciones» de aspectos parciales de la actividad primitiva del tipo social nuevo sacado a la luz por la nueva clase (Gramsci 1981a: 388)

Una vez consolidado el Estado que domina y dirige a la sociedad, según Gramsci, es necesario regresar a reestructurar las relaciones de los espacios subnacionales con el espacio nacional e internacional, de manera que se pueda desarrollar una actividad creadora del progreso histórico sustentado en las necesidades prácticas que necesita el capitalismo para su desarrollo. Aquí Gramsci plantea dos formas de organización, la que denomina centralismo democrático, que es un proceso de adaptación continuo dentro de un proceso de interrelación dinámico donde el Estado responde a las necesidades concretas de los espacios subnacionales; y el centralismo burocrático, donde el Estado tiene una incapacidad de articular eficientemente los espacios subnacionales. 
El centralismo democrático ofrece una fórmula elástica, que se presta a muchas encarnaciones; dicha fórmula vive en cuanto es interpretada y adaptada continuamente a las necesidades. Consiste en la búsqueda crítica de lo que es igual en la aparente disformidad, y en cambio distinto y aun opuesto en la aparente uniformidad, para organizarlo y conectarlo estrechamente a aquello que es similar, aunque de una manera tal que esta organización y esta conexión aparezcan como una necesidad práctica, «inductiva», experimental y no como resultado de un proceso racionalista, deductivo, abstracto, es decir, propio de los intelectuales puros —o puros asnos- Este lento y continuo trabajo por separar el elemento «internacional» $\mathrm{y}$ «unitario» en la realidad nacional y localista es, en esencia, la acción política concreta, la única actividad creadora de progreso histórico. Exige una unidad orgánica entre teoría y práctica, entre capas intelectuales y masas populares, entre gobernantes y gobernados. Desde este punto de vista las fórmulas de unidad y federación pierden gran parte de su significado, mientras continúan siendo perniciosas en la concepción burocrática, partiendo de la cual no llegaremos a la unidad sino a un pantano estancado, superficialmente calmo y «mudo», ni tampoco a una federación sino a una «bolsa de papas», vale decir, a una yuxtaposición mecánica de «unidades» particulares sin nexos entre sí (Gramsci 2008b).

\section{LOS GRUPOS HEGEMÓNICOS Y EL SISTEMA TERRITORIAL A PARTIR DE LA POSREVOLUCIÓN}

En esta parte del ensayo tratamos de explicar la relación entre los grupos hegemónicos que tienen influencia en todo el sistema territorial a partir de leyes aplicables en toda la nación, política fiscal, política de redistribución del ingreso, política monetaria, política social, políticas sectoriales, entre otras; y los grupos locales, que tienen una capacidad territorial de acción más restringida.

Partimos de analizar la reconstrucción de la unidad nacional desde la posrevolución de 1910, debido a que en ese momento el proyecto nacional que venía operando el grupo hegemónico es derrotado por un movimiento social en armas y donde al finalizar el 
conflicto se reconstituye en gran medida el bloque hegemónico en un proceso que llevará varias décadas.

En México la construcción del proyecto nacional actual surge después de una guerra civil entre el bloque hegemónico compuesto por terratenientes, grupo de intelectuales, ejército, Iglesia y clase política, y los grupos excluidos liderados por grupos sociales de las clases media y alta ilustrada, a quienes no se les permitía acceder al poder mediante un juego democrático. El primero de ellos mantenía, en términos gramscianos, una dominación pero no una dirección, al no generar un proyecto nacional incluyente como fuente de legitimidad y liderazgo, sino que se ceñía básicamente a satisfacer sus intereses como grupo en el poder.

En el proceso de la posguerra civil se encuentra un escenario difícil para la construcción de un nuevo proyecto nacional debido a la gran diversidad de intereses de los grupos locales que no logran ser integrados como aliados por el grupo gobernante en turno y poder con ello conformar un proyecto que tenga consenso, puesto que mantener el monopolio de la fuerza por el Estado requiere de alianzas y de consenso social.

La Revolución de 1910 no estalló en seco. Primero el propio régimen preparó el terreno con cambios económicos —el innegable crecimiento de las comunicaciones, la minería, la industria, la agricultura comercial, el intercambio con el exterior-, pero negándose a hacer inevitables los ajustes políticos. La oposición primero intentó la política y solo cuando no le quedó alternativa recurrió a la fuerza. El Partido Antirreeleccionista buscó agotar las instancias legales e incluso le propuso al dictador Porfirio Díaz someter en 1910 a la verdadera prueba de las urnas no a la Presidencia sino apenas a la Vicepresidencia. Todo resultó inútil. La oligarquía, los intereses creados, se burlaron de quienes les desafiaron, simplemente consideraron a Madero patético, absurdo, un payaso al que ni siquiera valía la pena eliminar sino apresar, humillar y, finalmente, ignorar. Cuando, tras la caída de Ciudad Juárez, 
quisieron negociar el tigre ya estaba fuera de la jaula. La Revolución consumió miles de vidas y aniquiló a la clase terrateniente, a los bancos y a las grandes empresas petroleras extranjeras antes de permitir el retorno del orden (Meyer 2006).

El proceso de reconstrucción de la unidad nacional fue complejo debido a los múltiples intereses y demandas que se interrelacionaron en la lucha armada, que fueron desde movimientos campesinos con demandas por la tierra, como el encabezado por Emiliano Zapata, los grupos de intelectuales y clase alta liderados por Francisco I. Madero, grupos de socialistas y anarquistas herederos de los Flores Magón, grupos políticos locales como los norteños de Carranza y Obregón, hasta líderes sociales como Francisco Villa surgidos desde el bandolerismo sin demandas sociales ni perfil ideológico definido, entre otros.

En la práctica se da una cuestión sui géneris en la construcción del nuevo proyecto de nación donde los intelectuales orgánicos emergen del ejército y se convierten en la clase política posrevolucionaria, siendo los que dirigen el nuevo proyecto. Esto ha generado una condición con muchas limitantes para el desarrollo de una economía capitalista eficiente, puesto que la clase empresarial industrial, que debía ser uno de los grupos sociales que dirigieran el proceso, está ausente, no por exclusión sino por su inexistencia, y conforme va apareciendo, creciendo y consolidándose lo hace totalmente subordinada a la clase política.

Los intelectuales ligados al ejército empiezan por fincar una dominación básicamente a partir de la fuerza, y a construir alianzas que de manera burocrática —en términos gramscianos- logran imponer su orden y empiezan a reconstituir un proyecto nacional creando nuevas fuerzas que nacen corporativizadas, construyendo un partido político fuerte mediante la fusión de un grupo de partidos locales y por lo tanto un proceso de negociación con diversas fuerzas de estas características espaciales. 
Se recurrió al concepto de populismo para tratar de entender la formación de estructuras políticas guiadas generalmente por dirigentes carismáticos con un amplio arraigo popular. Así se movilizaron grandes masas sociales en alianza con el Estado con vistas a emprender cambios significativos en las leyes y las instituciones por la senda del nacionalismo. El punto sustancial fue que los grupos sociales convocados por el populismo no logran convocar una alternativa política autónoma y, por consiguiente, se plegaron a los designios de los gobernantes. De esta manera se formó el mando autoritario con una amplia legitimidad (Fernández 2007: 63).

La intelectualidad política fue la que encabezó el nuevo proyecto de nación y subordinó a los grupos sociales tradicionales, como los terratenientes, permitiendo el reparto agrario pero a la vez creando una central campesina corporativizada como aliado esencial; cooptará al movimiento obrero a través de sus dirigentes cediéndoles espacios dentro del aparato de Estado y creando una central obrera corporativizada. Una nueva estructura de funcionarios públicos leales al nuevo proyecto de nación fueron captados del movimiento sindical, asimismo corporativizó a los profesionales independientes, pequeños comerciantes y prestadores de diversos servicios a través de la Confederación de Organizaciones Populares, CNOP. En aquel país rural y agrícola los empresarios industriales eran escasos y se irían formando en el proceso de maduración del nuevo proyecto nacional.

La construcción de este proyecto nacional forma un centralismo burocrático — según Gramsci, todo sistema capitalista genera un sistema político centralista— donde se inicia un proceso de mediación entre el partido de Estado, las instituciones gubernamentales y los grupos empresariales; mediación en la que todos promueven sus intereses buscando un equilibrio para mantener la estabilidad política que le permitía su 
reproducción social. Los intelectuales que surgieron del ejército posrevolucionario logran esa organicidad y se constituyen en la parte que lidera al bloque hegemónico.

\begin{abstract}
Esa organicidad solo podría conseguirse si los intelectuales hubieran elaborado y hecho coherente los principios y los problemas que planteaban aquellas masas con su actividad práctica, constituyendo así entre unos y otros un bloque cultural y social (Gramsci 1981d: 370).
\end{abstract}

Este bloque hegemónico tiene conflictos cuando van emergiendo nuevos grupos con intereses que no pueden incluirse dentro de su agenda, entre ellos está el grupo empresarial surgido del proceso de industrialización, la clase media que empieza a no tener ascenso social porque los espacios dentro de la burocracia estatal se van saturando, los campesinos empobrecidos, los movimientos sindicales que demandan nuevas prácticas democráticas, la ruptura de la clase política, los intereses de grupos sociales locales, las aspiraciones de intervención en la vida pública de las Iglesias, así como nuevos movimientos sociales ecologistas, de género, etcétera.

En la construcción del México posrevolucionario la unidad nacional fue un proceso complicado debido a la multitud de intereses locales que habrían de darles cabida para lograr la estabilidad y gobernabilidad del país, lo que se logró mediante la constitución de un partido de Estado donde se le dan concesiones a los grupos hegemónicos locales. Sin embargo, conforme se va iniciando e instaurando el sistema político, el grupo hegemónico, dirigido por burócratas, adopta un sistema presidencialista con una alta concentración del poder respaldado por un partido de Estado.

El papel que jugaron de manera protagónica las fuerzas locales para dar gobernabilidad al nuevo régimen fue rápidamente desplazado por el sistema presidencial. 
El diseño institucional fue planteado de tal manera que el poder iba de arriba abajo, así que los territorios, primero dominados por fuerzas caciquiles con amplia autonomía en el primer periodo posrevolucionario, paulatinamente fueron acotados por el sistema presidencialista, que prácticamente designaba a los candidatos del partido de Estado, a su sucesor, a los del poder legislativo federal, y a los gobernadores; los gobernadores a su vez nombraban a los candidatos para el legislativo local y las planillas de los ayuntamientos.

El diseño institucional se caracterizó por un amplio grado de incertidumbre, debido a que el sistema de reglas escritas era cotidianamente rebasado por las decisiones y la voluntad personal del presidente de la República, gobernadores o presidentes municipales.

La clase política, dependiendo de cálculos personales, lealtades y percepción de la realidad, tomaba decisiones a veces tan drásticas como la matanza de Tlatelolco, durante el movimiento estudiantil de 1968; financió a grupos de choque para enfrentar a los movimientos sociales que tiene su momento culminante en el «halconzazo» de 1971, matanzas de campesinos en diversas entidades del país, de igual forma era cotidiana la destitución de gobernadores y presidentes municipales a juicio del inmediato superior fáctico, en consecuencia la soberanía de los estados era letra muerta.

Es claro entonces que el proyecto nacional resulta muy diferente en los diversos ámbitos del territorio, puesto que depende de cuáles grupos hegemónicos locales logran establecer el vínculo con el poder central para detentar el poder y lograr establecer la hegemonía local, dado que el diseño del sistema político ha mostrado una gran inercia para lograr el cambio en cada territorio, porque no solo importa el consenso local para acceder al poder sino también los vínculos con los grupos políticos centrales; lo anterior se resume en lo que planteaba el cacique regional de San Luis Potosí, Gonzalo N. Santos: «para mantener el poder en tu estado debes de hacerle creer al gobierno federal que tienes mucha influencia 
en tu región, y en tu región deben creer que estás en muy buena relación con el gobierno federal». Este personaje, extremo en actitudes —que se multiplica por el proceso y cultura política del México posrevolucionario- dejó escritas sus memorias, que se publicaron posmórtem en 1987 por la editorial Grijalvo; es un claro ejemplo de lo que fueron los grupos en el poder local. Monsiváis, con el agudo ingenio que le caracteriza, comenta tales memorias en uno de sus artículos en cuyo título retoma cierta expresión de este personaje que define la moral como el árbol que da moras.

Este tipo de autonomías caciquiles desató movimientos sociales de resistencia, por ejemplo la movilización del Frente Cívico Potosino liderado por el Dr. Salvador Nava, que en 1958 obtiene «el primer triunfo electoral municipal de oposición frente al poderoso partido de Estado».

De este modo en algunas regiones, con el peso de los inamovibles grupos políticos, algunos grupos negociaron hábilmente y aprovecharon las ventajas locales, de esta manera logran promover proyectos regionales vinculados con el modelo de desarrollo central, aunque en un contexto de alta incertidumbre debido a que la fuente de reglas provenía de la visión y del estado de ánimo del Ejecutivo federal y/o estatal en turno, incluso hasta del presidente municipal.

Dentro de los poderes locales el gobernador aparece como una figura de fuerza política que anula los otros poderes y establece alianzas personales con los grupos políticos y económicos locales con tal alto grado de arbitrariedad que le permite vincular lo público con lo privado en la medida de sus intereses estrictamente personales, pasando por encima a los del grupo central en el poder. El gobierno central intenta revertir estos efectos perversos de la autonomía local de los gobernadores designándoles desde las estructuras centrales del partido de Estado, buscando que de inicio no tengan fuertes nexos con los 
poderes políticos y económicos locales con el fin de que respondan a los intereses nacionales de una manera más eficiente (Madrazo 1985).

Además este proceso de exclusión implícito en el diseño institucional moldeó una cultura política de apatía en amplios grupos de la sociedad, quienes si contravienen la voluntad del grupo hegemónico en el poder enfrentarán la violencia del Estado, por ello optan por la práctica política denominada «cargada», que en el lenguaje popular significa esperar las señales desde el partido de Estado para apoyar al que tiene mayores posibilidades de ocupar las estructuras del poder.

Tuvieron que ser muy grandes las afrentas, o por ser demasiado excluidos de los beneficios, que distribuyó el grupo hegemónico lo que provocó que surgieran movimientos sociales de resistencia, a la vez que lentamente se fueron consolidando los partidos políticos de oposición con aquellos grupos que no tenían ya cabida dentro del sistema de partido de Estado, ya fuera por fuertes divergencias ideológicas, porque no existían más espacios de poder que repartir o porque en los territorios los grupos centrales habían depositado el poder en grupos que no contaban con el consenso necesario y suficiente; así encontramos grupos de izquierda y derecha que tienen fuertes divergencia ideológicas con el Partido Revolucionario Institucional, PRI, grupos de profesionistas que no tuvieron acceso a los cargos públicos desde el partido de Estado, movimientos campesinos que demandaban tierra o servicios públicos, y un movimiento obrero que no se siente representado por las organizaciones corporativas.

El proceso de alternancia política inició en los gobiernos locales en los años ochenta, cuando son el escenario en el cual comienzan a tener presencia las fuerzas políticas de oposición y donde los grupos políticos hegemónicos empiezan a sufrir la resistencia de los grupos excluidos, y a enfrentar su propia ineficiencia a partir del 
monopolio del poder; este ascenso se vuelve evidente en las elecciones presidenciales de 1982: se le reconoce al Partido Acción Nacional, PAN, haber obtenido 17\% de la votación; continúa en 1983 cuando además gobierna 31 municipios, dentro de éstos se cuentan importantes capitales estatales; el punto culminante de este proceso ocurre en Baja California en 1989, cuando el Partido Acción Nacional gana al partido de Estado la primera gobernatura después de sesenta años de monopolio sobre todas ellas, de acuerdo con datos de Madrazo (1985) y Fernández (2007).

Fuertes movimientos sociales regionales emergían como resistencia en contra de los grupos hegemónicos locales —el movimiento navista en San Luis Potosí, el de Soriano en la capital oaxaqueña y la Confederación Obrero Campesina Estudiantil del Istmo de Oaxaca, el movimiento social y electoral del Partido Popular Socialista en Nayarit a mediados de los setenta, el movimiento campesino en Chiapas iniciado en los setenta que tiene su momento culminante con el alzamiento indígena de 1994, los movimientos armados en Guerrero iniciados por Lucio Cabañas y que en la actualidad continúan con el Ejército Popular Revolucionario, entre los principales-, que en el contexto de un Estado autoritario, primero bajo la figura del caciquismo local y después dentro del binomio centralismo-caciquismo, se nombraba y mantenía a los gobernantes locales independientemente de la opinión de amplios grupos de la población.

El reacomodo de los grupos en el poder debido al quiebre del modelo económico de sustitución de importaciones con alta intervención del Estado por el de una economía abierta con una reducción del Estado acompañado por el liderazgo de un nuevo grupo político «tecnocrático», provocó una ruptura en el liderazgo del bloque hegemónico. Por otra parte, un grupo de empresarios que no sienten representados sus intereses dentro del grupo hegemónico va a intentar aliarse con el cada vez más pujante Partido Acción 
Nacional, que rápidamente avanzó en la conquista de gobiernos locales gobernando un importante grupo de ciudades grandes y medianas desde mediados de los noventa. Todos estos procesos van acotando la capacidad de maniobra del grupo político hegemónico, a la vez que fuertes movimientos sociales vienen erosionando la capacidad de dirección de dicho grupo.

\begin{abstract}
No por casualidad, los últimos veinte años de la vida política se han destacado por la referencia continua de los actores políticos a los desajustes existentes y los cambios requeridos por la Constitución política. A medida que fueron haciendo su aparición y se han fortalecido nuevas alternativas encarnadas en grupos, movimientos y partidos políticos, el modelo político organizado en torno al eje centralista del presidencialismo fue rindiendo beneficios decrecientes hasta desembocar en resultados subóptimos desde el punto de vista del mantenimiento de la estabilidad política y de la producción de toda clase de bienes públicos. De este modo concluyó el periodo de gobernanza autoritaria (Valdés 2007: 200).
\end{abstract}

La alternancia política en México en el año 2000 planteó las expectativas de un cambio de sistema donde se replantearía el bloque hegemónico y donde la parte empresarial jugaría un papel de dirección dentro del grupo hegemónico, pero salvo la mayor influencia de algunos cuantos empresarios que continuaron demandando privilegios personales, la estructura hegemónica solo tuvo cambio de personas y no de grupos ni de prácticas ni proyectos. El partido corporativizado, PRI, mantuvo el control de muchos territorios a partir de mantener gobiernos estatales y municipales de manera mayoritaria en todo el país.

El PAN en el poder tuvo que pactar la gobernabilidad con el PRI, por lo tanto el grupo hegemónico se mantiene intacto y el proyecto nacional permanece dentro del parámetro gramsciano de «centralismo burocrático». 
Al no existir un nuevo grupo hegemónico que sea capaz de replantear las relaciones dentro del sistema territorial y rotas las reglas no escritas que controlaban los excesos de los poderes locales, en muchos territorios se ha reactivado el efecto perverso de los caciquismos locales, cuyo dominio sobre la sociedad civil se sustenta principalmente en métodos de intimidación y de violencia.

A pesar de lo anterior, también existe una efervescencia de algunos grupos de poder local para insertarse en un nuevo proceso de participación y cooperación local, sin embargo al no haberse desmontado el sistema político es difícil encontrar mecanismos institucionales que permitan fluir libremente ideas y prácticas innovadoras.

En el rubro de acciones innovadoras encontramos que muchos gobiernos locales, a pesar de las restricciones institucionales y estructurales, crean un conjunto de acciones que buscan lograr mejor calidad en los bienes públicos que ofrecen e intentan incorporar iniciativas ciudadanas para generar mayor gobernabilidad en sus territorios.

\footnotetext{
Ahora los gobiernos subnacionales exigen participar en las decisiones y la consecuente ampliación de sus límites de maniobra. Al debilitarse la cohesión central basada en un presidencialismo fuerte — situación que empezó a gestarse desde los últimos gobiernos del PRI— cada actor en la arena política exige mayor protagonismo. Infortunadamente las reglas del juego han mostrado su agotamiento y ya no responden a esta dinámica nueva, en la que los desacuerdos y conflictos se incrementan y hacen evidentes mientras las vías de solución no terminan de ser claras (García 2007: 109).
}

$\mathrm{Y}$ sin embargo los municipios urbanos se mueven. Inicialmente se trataba de experiencias muy aisladas, pero poco a poco observamos un mayor número de gobiernos locales urbanos que 
desarrollan una capacidad innovadora de gestión e impulso de una acción pública endógena (Cabrero 2006: 150).

No obstante, por otro lado, encontramos gobiernos locales como el de Oaxaca, donde el conflicto de 2006 entre el gobierno del estado y la Asamblea Popular del Pueblo de Oaxaca evidenció a todas luces que se trataba de un problema de exclusión política, económica y social, donde para resolver la confrontación los métodos de violencia extralegal de los grupos de poder local y finalmente el uso de la violencia legal del Estado fueron los mecanismos para intentar dirimir dicho conflicto.

\section{CONCLUSIONES}

Metodológicamente, dentro del análisis político no pueden ni deben ser disociados tanto los procesos de acceso al poder y su conservación como el ejercicio de gobierno a partir de políticas públicas, debido a que la manera como se ejerce el poder desde el Estado depende de cómo se estructura y reestructura el bloque hegemónico en el poder, aunado los proyectos que se plantean; todo ello determina qué grupo impone su hegemonía para establecer los mecanismos de dominio y dirección sobre el resto de la sociedad, así los procesos corren simultáneamente afectándose de manera mutua.

Si se analizan los procesos históricos de construcción del Estado nación se observa que se requiere, en un primer momento, que el poder del Estado centralice e imponga la unidad nacional, de tal forma que genere una estructura institucional capaz de crear las reglas del juego necesarias para el pleno desarrollo de una economía de mercado. En este primer momento, los espacios subnacionales deben subordinarse para consolidar la estructura de un Estado nación. En un segundo momento, con reglas del juego claras, los 
espacios subnacionales reestructurados conforme a las necesidades de un Estado nación deben tener mayor autonomía para dinamizar el desarrollo, de manera que las iniciativas locales innovadoras permitan el desarrollo de los territorios, de igual forma los grupos de poder local tendrían que estructurar su dominio a partir de una capacidad de dirección para que pudieran generar el consenso social necesario, tanto al interior del grupo dominante como del grupo subordinado.

En México se da un proceso de reconstitución del Estado nación después de la Revolución mexicana, puesto que dentro de cualquier proceso revolucionario no existe un bloque hegemónico, ya que no se da el consenso, y la clase política se disputa de manera violenta la hegemonía para imponer un nuevo proyecto nacional.

En este sentido, en el desarrollo histórico de México, la reconstrucción de la unidad nacional después de la Revolución mexicana fue un proceso con demasiadas complicaciones por la multitud de intereses y visiones de los grupos que participaron en el movimiento armado. No hubo un grupo social previamente consolidado económicamente y con la base social suficiente que dirigiera la reconstrucción del Estado. El ejército posrevolucionario proveyó los hombres que constituyeron la clase política dirigente que construyó alianzas con los grupos de poder local —el momento culminante fue la constitución de Partido Nacional Revolucionario-. Esta alianza ejército-grupos de poder local permitió el uso arbitrario del poder en las regiones, generalmente sustentado en la intimidación y la violencia.

Posterior a la consolidación del partido de Estado, los grupos locales que se vincularon con la estructura centralista fueron ungidos con el poder local, impidiendo en muchos casos que la dirección política y económica recayera en aquellos grupos locales carentes de vínculos con el poder político central, aunque tuvieran un proyecto con ideas 
innovadoras que permitirían el desarrollo del territorio o contaran con un mayor consenso social.

Así encontramos que dentro del periodo que va de la derrota del Ejército Convencionista — Villa y Zapata — hasta el periodo de alternancia política del año 2000 existen tres etapas diferenciadas de relación entre los grupos locales de poder y los grupos que detentan el poder central. La primera que parte de la creación de la Constitución de 1917 hasta la conformación del partido de Estado, donde los grupos locales gozan de gran autonomía debido a la necesidad del poder central de apoyos para mantenerse en el poder, aunque la hegemonía local fuera impuesta generalmente por métodos violentos existiendo en los territorios diversos grupos en las disputas. La segunda etapa va de la constitución del partido de Estado hasta finales de los años setenta, en ésta se subordinan los grupos de poder local al poder central de tal manera que el acceso al poder local depende de la intensidad de la relación y del grado de lealtad expresados hacia el gobierno central; sin embargo la mediación del poder central propicia que los grupos locales instaurados en el poder no tengan grupos que se lo disputen de manera violenta ni mediante mecanismos democráticos. En la última etapa, a partir de los ochenta hasta la alternancia del año 2000, los grupos locales empiezan a disputarse el poder: grupos subordinados, a pesar de que no contar con las relaciones suficientes con el poder central que los excluía, comenzaron a utilizar el sistema de partidos políticos como un espacio privilegiado de disputa por el poder, aprovechando la incipiente pero progresiva apertura producto de las reformas políticas.

El quiebre del modelo autoritario que produjo la alternancia política del año 2000 tiene sus orígenes tanto en el fracaso del modelo económico de economía cerrada — que inició un proceso de reestructuración hacia un modelo de economía abierta—, como por el 
movimiento social de los grupos excluidos del poder político y del desarrollo económico y social. El movimiento político electoral de resistencia inició a principios de los ochenta en los territorios subnacionales —-municipios y estados—en donde las imposiciones políticas han sido hecho cotidiano, de manera que los partidos políticos, aliados unos con los movimientos sociales y otros con los grupos de poder local, empiezan a ganarle posiciones al partido de Estado, esto les permite crecer y acumular la fuerza política suficiente para disputar el puesto central dentro del modelo autoritario que es la presidencia de la República, cuestión que se acelera con la ruptura que se da al interior del partido de Estado entre los denominados tecnócratas y los políticos encabezados por Cuauhtémoc Cárdenas, que en 1988 hace tambalear al partido de Estado, pero que termina capitalizando el PAN con Vicente Fox en el año 2000.

Dentro del sistema político autoritario quedaron varadas las iniciativas para el desarrollo territorial, no se generaron las estructuras institucionales que propiciarían las condiciones para que fluyeran las iniciativas de dirección innovadoras y elásticas que permitieran la reproducción y ampliación de la clase empresarial moderna dentro de los grupos de poder local. Por las evidencias de los movimientos sociales y la activa participación de los grupos de poder local en el destroncamiento del sistema autoritario, existe una energía social que puede empujar el desarrollo desde lo local, aunque se requieren varias condiciones: reestructurar las reglas del juego democrático; crear una nueva estructura institucional y un nivel de cultura política de la población, para impedir que los grupos caciquiles de poder local impongan su dominio con el fin de satisfacer intereses personales y del pequeño grupo que ejerce la hegemonía en el territorio, y saqueen o dilapiden los recursos públicos en su visión nula de gobernanza. 
En el actual proceso que denominamos de transición democrática es necesario avanzar de manera paralela tanto en la estructura institucional nacional como en el fortalecimiento de la autonomía subnacional; para lograr esto se requiere la construcción de un diseño institucional que garantice certidumbre a la reproducción social del capital en el contexto de una economía abierta y globalizada, el cual requiere como necesidad reproducir y ampliar la clase empresarial dentro del contexto de unidad nacional mediante las condiciones que permitan la disputa por el poder dentro de los parámetros democráticos, y esto se puede lograr rearticulando los espacios subnacionales en un proyecto que impulse el desarrollo a partir de procesos de innovación política, económica y social en tales espacios.

El impulso de un modelo de desarrollo local debe fundarse y estructurarse con base en alianzas con grupos de poder local que tengan la capacidad de comprender que la dirección política, social y económica de un territorio debe estar sustentada en abrir las puertas a la innovación y generar redes de colaboración en el territorio. Para generar proyectos de largo plazo deben existir incentivos en la estructura institucional para todos estos grupos: reglas del juego democrático para acceder al poder, consejos de participación ciudadana como órganos de consulta necesarios, incentivos fiscales, mayores recursos y funciones a los gobiernos locales, así como trasparencia y rendición de cuentas.

Las estrategias de desarrollo se deben trabajar con los grupos sociales de poder y grupos sociales con capacidad de gestión para generar nuevas propuestas que puedan entrar en la agenda de los gobiernos locales y en la visión de los intermediarios que procesan las demandas de cara al poder central.

En términos de Gramsci, los intelectuales que están interesados en impulsar proyectos de desarrollo local deben vincularse forzosamente con el grupo de poder local, para que impulse y coloque en su agenda una estrategia de esta naturaleza, y desde sus 
Revista Pueblos y Fronteras digital

Iniciativa empresarial y desarrollo local en América Latina
Núm. 6, Diciembre 2008 - Mayo 2009

http:// www.pueblosyfronteras.unam.mx

actividades profesionales, económicas, sociales y culturales, generen el entorno de dirección y consenso para un proyecto de este tipo. 


\section{BIBLIOGRAFÍA}

Aguilar, Luis, 1996, «Estudio introductorio». En El estudio de las políticas públicas, pp. 15-74, editado por el autor. Miguel Ángel Porrúa, México.

Arreola, Álvaro, 1985, «Elecciones municipales». En Las elecciones en México: Evolución y perspectivas, coordinado por Pablo González Casanova. Siglo XXI, México.

Buci-Glucksman, Christine, 1979, Gramsci y el Estado. Siglo XXI, México.

Cabrero Mendoza, Enrique, 2006, Acción pública y desarrollo local. Fondo de Cultura Económica, México.

Coronilla, Raúl y Arturo del Castillo, 2000, «El cambio organizacional». En Reformando al gobierno: una visión organizacional del cambio gubernamental, coordinado por David Arellano, Enrique Cabrero y Arturo del Castillo. Miguel Ángel Porrúa, México.

Dror, Yehezekel, 1996, «Prolegómenos para las ciencias de políticas». En El estudio de las políticas públicas, pp. 119-148, editado por Luis F. Aguilar. Miguel Ángel Porrúa, México.

Fernández, José, 2007, «Democracia contra gobiernos de elite». En Democracia y gobernabilidad: Agenda para el desarrollo, pp. 55-66, coordinado por José Luis Calva. Miguel Ángel Porrúa,Universidad Nacional Autónoma de México, México.

Gallicchio, E., 2004, El desarrollo económico local en América Latina. ¿Estrategia económica o de construcción de capital social? En http://desarrollolocal.org [consulta: enero de 2004]. 
García, Rodolfo, 2007, «Federalismo y descentralización: problemática y perspectivas en México». En Democracia y gobernabilidad: Agenda para el desarrollo, pp. 105120, coordinado por José Luis Calva. Miguel Ángel Porrúa,Universidad Nacional Autónoma de México.

Gramsci, Antonio, 1981a, «La formación de los intelectuales». En Antología, pp. 388-395, selección, traducción y notas de Manuel Sacristán. Siglo XXI, México.

1981b, «Estatolatría». En Antología, pp. 315-316, selección, traducción y notas de Manuel Sacristán. Siglo XXI, México.

1981c, «El problema de la dirección política en la formación y el desarrollo de la nación y el Estado moderno en Italia». En Antología, pp. 485-487, selección, traducción y notas de Manuel Sacristán. Siglo XXI, México.

1981d, «Relaciones entre ciencia-religión-sentido común». En Antología, pp. 367381, selección, traducción y notas de Manuel Sacristán. Siglo XXI, México.

2008a, «Debilidad nacional de la clase dirigente». En http://www.gramsci.org.ar/index.htm [consulta: enero de 2008].

2008b, «Sobre la burocracia». En http://www.gramsci.org.ar/index.htm [consulta: enero de 2008].

Grossman, R. H. S, 1986, Biografía del estado moderno. Fondo de Cultura Económica, México.

Madrazo, Jorge, 1985, «Lecciones de gobernadores». En Las elecciones en México: Evolución y perspectiva, coordinado por Pablo González Casanova. Siglo XXI, México. 
Meyer, Lorenzo, 2006, «El 20 de noviembre o la nueva insurgencia». En http://jupiter1962spain.spaces.live.com/blog [consulta: enero de 2008].

Moncayo, E., 2002, «Enfoques teóricos, evolución de las políticas regionales e impacto territorial de la globalización». En http://www.eclac.org/publicaciones/xml/5/11885/sgp27.pdf [consulta: octubre de 2007].

Monsiváis, Carlos, 2000, «La moral es un árbol que da moras». Letras Libres, pp. 24-27, diciembre. México.

Sartori, Giovanni, 2003, La política: Lógica y método en las Ciencias Sociales. Fondo de Cultura Económica, México.

Valdés Ugalde, Francisco, 2007, «La reforma que no fue y la democracia constitucional». En Democracia y gobernabilidad: Agenda para el desarrollo, pp. 199-207, coordinado por José Luis Calva. Miguel Ángel Porrúa, Universidad Nacional Autónoma de México.

Vázquez, Antonio, 1999, Desarrollo, redes e innovación. Editorial Pirámide, Madrid.

Fecha de recepción: 12 de febrero de 2008

Fecha de aceptación: 24 de abril de 2008 